\title{
Flipping Roles: Exploring the Impact of a Flipped Classroom Method on the Student Success Rate in a Pharmacology Course
}

\author{
Melissa J. Kennedy ${ }^{1}$ \\ ${ }^{1}$ Nursing Faculty, Southwestern Michigan College, Dowagiac, Michigan, USA \\ Correspondence: Samuel P. Abraham, Associate Professor of Nursing, 1001 Bethel Circle, Bethel University \\ School of Nursing, Mishawaka, Indiana, 46545, USA.
}

Received: February 15, 2019

Accepted: March 5, 2019

Online Published: March 8, 2019

doi:10.20849/ijsn.v4i1.553

URL: https://doi.org/10.20849/ijsn.v4i1.553

\begin{abstract}
There are an estimated 1.05 million job postings across the United States for registered nurses by the year 2022 . To answer for this demand, nursing programs across the nation are undertaking quality improvement initiatives to increase student success and graduation rates. Referencing Ausebel's Assimilation Theory and motivated by the research question: Did the introduction of the active, flipped classroom make a difference in student success rates when compared to the student success rates in the traditional class room in a pharmacology course a retrospective data analysis was performed. The relationship between student success rates in the flipped classroom were compared to the relationship of student success rates in the traditional classroom based on the comprehensive final examination. There were 169 final examination scores extracted for data analysis 90 traditional classroom, 79 flipped classroom examination scores were extracted for data analysis. Independent $t$-tests were used to compare the means of the final examination scores in the traditional classroom to the means of the final examination scores in the flipped classroom. The findings of the research indicated there was no significant difference between the mean scores of the traditional classroom $(\mathrm{M}=81.7, \mathrm{SD}=6.3)$ and the mean scores in the flipped classroom $(\mathrm{M}=80.1, \mathrm{SD}=7.8, \mathrm{t}(135)=1.39, \mathrm{p}=.15)$. Based on the results of this study, it is concluded that the flipped classroom can be utilized as an alternative method of instruction in the course as well as in other courses within the nursing program.
\end{abstract}

Keywords: flipped classroom, active learning, student success

\section{Introduction}

According to the National League for Nursing (NLN, 2015), approximately only $62 \%$ of those students who enroll in the first semester of a two year nursing program will be enrolled the second year of instruction. The Bureau of Labor Statistics (2012) estimated there will be 1.05 million job postings for registered nurses (RN) by the year 2022. With the high demand for future nurses, nursing schools must answer the call for future nurses. One way to answer that call is by increasing student success rates in the classroom. Student success rates may be improved by the concept of "flipping the classroom."

Flipping the classroom is a term that is becoming a cliché in the world of education. Some educators are not only unsure how to flip the classroom, they may also be cautious to hand the classroom over to the students. Flipping the classroom began in a high school chemistry class where Bergmann and Sams (2012) prerecorded lectures. These lectures were considered homework. Having the lectures prerecorded allowed more class time to devote to more difficult and pressing class material by allowing time for problem-based learning guided activities (Della Ratta, 2015). Flipping the classroom may lead to increased student-instructor interactions, increased student-student interaction, and increased student knowledge retention and application abilities.

As a student progresses from core prerequisite classes to nursing courses, culture shock often sets in. Prior to entering a school of nursing, a student's primary path to success is through rote learning. Rote learning is a type of memorization that occurs by repetition (Concordia Online Education, 2015). Students quickly learn this method of learning will not lead them to success in nursing courses. Unfortunately, few students have been exposed to any other type of learning leading up to nursing school. To be successful in nursing school, students must learn to think critically. Critical thinking involves synthesizing and applying previously learned information (Foundation of Critical Thinking, 2015). To critically think the student must be able to take the information that was learned by rote memorization, break the information down into meaningful parts, and apply those meanings to situations. The 
act of critical thinking is often a learned skill rather than an inherited one. Nursing educators are often held responsible for teaching the student to think critically (Yildirim Ozkahraman, \& Karabudak, 2011).

One way to flip the classroom and increase critical thinking skills is introducing concept mapping in the classroom. Introduced by Novak in 1998, concept mapping has been a proven tool to help enhance critical thinking and move students away from rote memorization into meaningful learning (Ausubel, 1968). Ausubel (1968) believed that meaningful learning could only occur if the learner could relate information to existing concepts, thus rearrange and reorder the existing concepts to include new information (Yeo, 2014). Novak adopted Ausubel's assimilation theory consisting of five steps to learning in the creation of the concept map (as cited in Vancek, 2009).

The NLN (2016) has documented the largest attrition rates occur between the first and second years of instruction where there is a loss of $15-20 \%$ of students. Prior to the introduction of the flipped classroom and concept mapping, the school of interest for this study had a much higher rate of attrition than NLN's published average (see Table 1). In an effort to increase nursing student success rates at a rural community college in southwestern Michigan, Ausubel's assimilation theory along with Novak's idea of the concept mapping and Bergman and Sams flipped classroom were introduced into the Pharmacology I classroom. Pharmacology I is a 14-week course in the second semester of instruction at an associate degree nursing (ADN) program.

Table 1. Program Attrition rates. This table represents the program attrition rates over the past 6 semesters.

\begin{tabular}{lccc}
\hline \multicolumn{1}{c}{ Cohort } & $\begin{array}{c}\text { Initial Student } \\
\text { Enrollment }\end{array}$ & $\begin{array}{c}\text { Number of students } \\
\text { completed program }\end{array}$ & Attrition Rate \\
\hline Spring 2013 & 34 & 17 & $50 \%$ \\
Fall 2013 & 38 & 30 & $19 \%$ \\
Spring 2014 & 33 & 18 & $45 \%$ \\
Fall 2014 & 34 & 27 & $21 \%$ \\
Spring 2015 (9 students still in process) & 32 & 16 & -- \\
Fall 2015 (9 students still in process) & 39 & 21 & - \\
\hline
\end{tabular}

\section{Background of the Problem}

There is an astounding estimated increase in needs for RNs by the year 2022. Conversely, recorded by the NLN (2015), there is a decline in the number of nursing students successfully completing their course plans to sit for the national boards. With the increase in demand and decreases in student success, the RN shortage in 2022 could be catastrophic. Already in 2015, area healthcare institutions are seeing increased needs for qualified nursing applicants fill the overwhelming openings. A quick internet search revealed the three major hospital systems in the same 50-mile radius. Within these three systems there are 119 current job postings for nurses.

Due to the changes in healthcare delivery methods, many qualified RNs are seeking positions outside of the acute care setting. RNs are seeking full-time employment in the home care setting, outpatient centers, moving to RN care manager roles, and various other roles. Long hours and required holidays may be some reasons RNs are leaving the acute care setting and moving to other healthcare delivery settings. Positions in the acute care setting were once perceived to be jobs that provided great pay for fewer hours of work are now being reconsidered by many. As the population of RNs begin to age, and many baby boomer RNs are beginning to consider retirement, the glamour of the 12-hour shifts is fading these seasoned nurses are seeking work outside of the acute care setting. All of these factors are impacting the need for RNs in the acute care setting, thus increasing the demand on nursing schools to produce graduates.

With the exodus by RNs from the acute care settings, massive holes in RN staffing are beginning to further deteriorate the quality and safety of the acute care settings. With an estimated 1.05 million RN job postings in 2022, one must wonder how these vacancies will be filled. The easiest answer to the impending healthcare crisis of an $\mathrm{RN}$ shortage is to enroll and graduate more students within the higher education setting. Currently the estimated $38 \%$ attrition rate within ADN programs in the United States means it will be difficult to fill the need for RNs in healthcare (NLN, 2016).

To help address the issue of shortages among RN staffing in the acute care setting, institutions of higher learning are beginning to investigate alternative means of information and content delivery to the students. Flipping the classroom is a topic of great interest to researchers today. Concept mapping is one of the most talked about strategies being used in flipping the classroom. Concept mapping from Ausubel's theory of assimilation (Novak \& Gowin, 1984). Studies are abundant observing student satisfaction with the introduction of the flipped classroom 
and concept mapping, but little research is available or exists on the impacts of concept mapping on student success. Learners express mixed emotions about the flipped classroom. Schoening et al. (2015) concluded students preferred the passive strategies of content delivery like a lecture, however an increase in critical thinking and problem-solving abilities were displayed among those students involved in the flipped classroom setting. One of the concerns of the students involved in the study was fear of not mastering the content. George, Geethankrishnan, and D'Souza (2014) concluded that delivering content via conventional methods proved difficult in determining the ability for students to think critically. The introduction of concept mapping quickly allows the instructor to evaluate the student's ability apply critical thinking to course concepts.

With the impending crisis of nursing shortages in the United States, high quality, critically thinking, and successful nursing students are imperative. The initiation of the flipped classroom with the incorporation of collaborative concept mapping may be a way to produce those students. With the climbing demands and decreasing success rates of nursing students, all possible interventions must be explored as an answer to increasing nursing student success. This study aims to explore a relationship between flipping the classroom with concept mapping and student success.

\section{Review and Summary of Relevant Literature}

Many nursing students have the attitude of "Don't ask me to think - just give me the facts" (Palmer, 2007, p. 38). With the national average of over $30 \%$ of the students enrolled in a two-year nursing program not returning after their first year of instruction a call to action is required (NLN, 2016). The student's ability to critically think may be at the root of student success. Several interventions are being studied at higher education institutions to increase the nursing student success rate by increasing the student's ability to critically think. Some interventions aimed at increasing student success are designed around flipping the classroom. Concept mapping is one intervention being used across the nation to increase critical thinking skills (Clayton, 2006).

CINAHL and Proquest Dissertation and Theses databases were utilized to generate several results on the flipped classroom and concept mapping in nursing education. The literature searches were limited to the years $2010-$ 2016. Using the key terms "flipped classroom" and "nursing education" in the CINAHL database yielded 59 results. Narrowing the search using "flipped classroom" and "student success" yielded 38 results. Of the 38 results only three were research-based articles. The phrase "concept mapping" and "nursing education" yielded 1,828 results which were narrowed down adding the phrase "student success" to the original search which yielded in 169 results. Of the 169 results, six articles were research-based and focused on concept mapping in nursing education and the success of students. Using search terms concept mapping and flipped classroom did not yield any results in the CINAHL database. Similar results were found using the Proquest Dissertation and Theses database. Using the same search terms, four dissertations focused on "nursing education" and the "flipped classroom", while the terms "concept mapping" and "nursing education" and "student success" yielded 88 results. Of the 88 results, nine dissertations were determined relevant to the current study: four focused on a flipped classroom or some type of mixed instruction, two focused on the students' perception of teaching styles, and two focused on concept mapping and increased student scores. Many themes emerged from the review of literature. Following are the themes addressed in this literature review: active learning, flipped classroom, and concept mapping.

\subsection{Active Learning}

Active learning challenges traditional learning by taking the focus away from the instructor at the front of the classroom and turning the focus to the core of the classroom: the students. Given that several forms of active learning exist, creating a definition to encompass all of them may be impossible. Some, but not limiting, active learning strategies in nursing education include simulation labs, student-led lectures, case studies, flipped classrooms, and group work activities. Many nurse educators believe there are several benefits when incorporating active learning into the classroom. Some of the benefits associated with active learning include encouraging nursing students to become engaged in the learning process, taking personal responsibility for their own learning, learning to work collaboratively and even foster clinical reasoning and critical thinking. Student-led teaching concepts helped increase student engagement and in-depth presentation of topics often sparked professional and collegial dialogue between the participants (Stevenson \& Gordon, 2014). Overall course content mastery levels were unaffected when students were the ones leading discussions on various maternal-child nursing topics. While there were no reported increases in student exam scores in this study, overall student course satisfaction increased.

Waltz, Jenkins, and Han (2014), compiled sources from the available literature to investigate active learning and its effectiveness in health education settings. Within CINAHL and MEDLINE, 22 articles identified and analyzed active learning strategies for effectiveness. Some comparisons investigated by Waltz et al. (2014) included internet learning versus traditional learning, group discussions, the use of clickers in the classroom, and 
interactive/collaborative learning strategies, such as interactive classroom games. All of the studied active learning strategies had indications of high student engagement and satisfaction, but little significant data that supported increased student learning and success. Similar results were reported by Schoening et al. (2015). The introduction of collaborative learning in an obstetric nursing course included the use of unfolding case studies that consisted of sample test questions, definition of terms and collaborative quizzing. A three-phase project took place over the course of four years where 193 traditional four-year bachelorette nursing students and 153 accelerated bachelorette nursing students participated. In the pilot stage of the study 84 of the participants were introduced to the collaborative learning environment. The second stage involved comparing 103 students enrolled in the traditional setting to 103 students enrolled in the collaborative learning. Finally, the implementation phase focused on fully implementing the collaborative learning environment. Each stage of the study compared student satisfaction and examination scores between the traditional and collaborative environment students. This comparison revealed students in the collaborative environment reported overall satisfaction with collaborative learning and examination mean scores were significantly higher $(87.13 \%$ versus $84.40 \%)$ in the collaborative setting versus the traditional setting (Schoening et al., 2015).

Based on a study by Toothaker (2016), of the five themes identified in a qualitative study, the most challenging learning environment for millennial students in the classroom is a disengaging instructor, as indicated by 12 of the 13 participants. In this study, 13 millennial students were interviewed in a one on one setting to determine what these students found engaging and meaningful learning experiences. Other themes that emerged included: physically present but being mentally dislocated, unspoken peer pressure, surface learning, and lack of trust. One way to increase engagement between the instructor and the student is to integrate active learning activities into the classroom (Toothaker, 2016). Based on the studies above, an interactive classroom promotes high student engagement, increased student satisfaction, and has shown to increase examination scores (Schoening et al., 2015; Waltz et al., 2014).

\subsection{The Flipped Classroom}

One of the more prevalent active learning strategies is the flipped classroom. Introduced by Bergmann and Sams (2007), flipping the classroom has taken educational settings by storm. What began as an observation, quickly became the pillar of modern teaching. Flipping the classroom is a pedagogical model employing video lectures, reading assignments, practice problems, and other digitally-based projects outside of the classroom while having interactive problem-solving activities conducted inside the classroom (Bergmann \& Sams, 2012). In the flipped classroom, the student receives much of the foundational knowledge ahead of class time in order to participate in the class activities (McDonald \& Smith, 2013). The flipped classroom requires students to take responsibility for their own learning. Bergman and Sams (2012) observed their high school chemistry students needing more time in the classroom for questions, answers, and help with their assignments. Due to this observation, the two decided to begin to record their lectures and post them online. Once all of the lectures were posted online, students were instructed and expected to access the lectures prior to class, eventually termed a flipped classroom by Bergmann and Sams (2012). Because all of the lectures were available online, the lectures became the homework and the previously expected homework became the in-class work. Prior to the initiation of the flipped classroom, Bergmann and Sams (2012) observed their students were unable to adequately complete assigned homework because they did not understand the material once they returned home. The flipped classroom changed all of that. Students were able to listen to the lectures at home and bring all their questions into the classroom. Class time was spent completing what would have been homework. Completing this work in the classroom allowed the students to ask questions in class and seek clarification as they were completing assignments.

The success of Bergmann and Sams (2012) has created excitement in higher education. As schools of nursing strive to produce highly motivated, competent entry level practitioners, new delivery methods of information are being explored. Realizing students were looking to be handed information for testing purposes and being unable to critically think through answers on the test, Edie (2014) flipped a medical-surgical classroom. Prior to the initial delivery of the flipped material, a student became very upset insisiting payment for the class was made to particpate in a lecture and not an online course. After the first, class period, that same student apologized and expressed effective learning and eagerness for the continuance of the course.

Quantitative research on the flipped classroom does not reveal statistically significant data to support students are more successful in the flipped classroom. However, it has also been cited, flipping the classroom does not decrease the overall scores in the course. Murray, McCallum, and Petrosino (2014) studied 53 physical therapy students between the years 2010 and 2011. In 2010, 23 students participated in a traditional lecture setting, while in 2011, the other 30 students participated in a flipped classroom setting. The flipped setting included voice lectures posted online that students were required to view prior to class. Both cohorts of students were given the 
same multiple-choice tests throughout the courses. The 2011 cohort had a slightly higher overall exam score mean, however this small margin did not prove to be statistically significant to indicate the flipped classroom yielded better performance on the multiple-choice exams, $\mathrm{p}=.19$ (Murray, McCallum, \& Petrosino, 2014).

Harrington et al. (2015) studied 82 undergraduate nursing students receiving two different teaching interventions. Students were randomly assigned to either a flipped classroom environment or a traditional learning environment. The students enrolled in the flipped classroom were expected to complete the online PowerPoint lectures prior to class, while those in the traditional classroom received the same information during class time. The flipped classroom students engaged in problem-based scenarios during the assigned face-to-face class time. Both groups of students tested at the same time, engaged in the same 24 quizzes, and received to same lecture information. While the flipped classroom students achieved slightly higher exam and quiz scores, the final exam means for both classes of students was 86.3\% (Harrington et al., 2015), indicating both groups mastered the content of the course. The results of Geist, Larimore, Rawiszer, and Al Sager's (2015) study also revealed statistically insignificant results when looking at a nursing pharmacology course. A total of 86 nursing students were studied over the course of a school year. In the fall of 2012, 40 students received traditional classroom instruction while 43 students in the spring of 2013 received flipped classroom instruction. Three-unit exams and one final exam were used as the basis of measurement. The two study groups received the same information and engaged in the same multiple-choice tests. While the flipped classroom students scored higher overall on the unit exams, the results of the final exam did not show a significant difference between the two test groups, $\mathrm{f}[1,86]=1.95, p=.167$ (Geist et al., 2015).

Thus far, statistical data does not reveal a significant difference in the performance of students engaged in a flipped classroom versus a traditional classroom. Of the literature reviewed on the flipped classroom in nursing education, little information was able to be gathered on the actual content being covered in the classroom. Activities the students in the flipped classroom participated in were not discussed in depth in any of the reviewed articles. All of the articles did indicate the students were required to view/listen to online PowerPoints prior to actual class meeting times. To be replicated, further research should indicate the actual methods of instruction and student engagement during class times.

Several dissertations exist on the topic of a flipped classroom, for example, Faretta (2014) conducted a study that included 64 participants. Thirty-two participants were studied in the traditional lecture style classroom, the remaining participants were placed in a flipped classroom. A t-test analysis resulted in $\mathrm{p}=.95$ which indicates no significant difference in scoring between a flipped classroom and a traditional classroom. Maxwell (2014) had similar results in a study evaluated 64 students. Thirty-two students were assigned to an online only classroom and 32 to a course that had the same online modules as the first group but also met regularly in a flipped classroom setting. In this study, the researcher compared the differences in the students' knowledge, skills, and attitudes (KSAs) in regard to quality improvement and patient safety. Using standardized testing items, no significant difference was found in either quality improvement or patient safety scores. An omnibus $(\mathrm{p}=.028)$ difference was found between the control and experimental group in regard to quality improvement KSAs that did not support a significant difference between the two groups (Maxwell, 2014). There was not a statistically significant difference in KSAs of patient safety (MANOVA, $\mathrm{p}=0.59$ ) between the two group; indicating both methods of teaching were equally effective in QSEN competencies (Maxwell, 2014).

\subsection{Concept Mapping}

Based on Ausubel's assimilation theory of learning, Novak and Gowin (1984) introduced concept mapping; Defined as a schematic diagram representing key concepts in a framework of propositions Novak and Gowin (1984) outlined criteria to help guide nurse educators in evaluating nursing student's understanding and concept links within their concept maps. Clayton (2006) conducted a literature review of the use of concept maps. Findings of the review focused on student knowledge, student perception, and faculty and staff perceptions of concept mapping. Overall, Clayton (2006) found the student's perceptions of concept mapping to be positive, enhancing their integration of knowledge and retention. Three of the studies confirmed higher exam scores when concept mapping was a part of the classroom curriculum. Faculty and staff also reported overall positive feedback in regard to concept mapping.

Many studies involving concept mapping focus on the increased ability of nursing students to engage in critical thinking and student perceptions of concept mapping. One such study focusing on critical thinking is that of Abel and Freeze (2006) where 28 students participated in a concept map intervention. Students completed a concept map and were scored based on their ability to describe client needs, nursing care, and relevant relationships. Total scoring indicated an understanding of the concepts being mapped. Faculty believed the students indicated 
increased critical thinking because they were not copying information from a text like they would when creating a traditional care plan. Students reported feeling knowledgeable on the subjects being studied and expressed an overall satisfaction of the concept mapping process and knowledge acquisition. Atay and Karabacak (2012) conducted a study to determine if putting the traditional care plan in a concept map format would generate higher levels of critical thinking in nursing students. Atay and Karabacak (2012) utilized the California Critical Thinking Disposition Inventory scores to compare scores of the students using the traditional care plan and scores of students using concept mapping care planning. Pre and post critical thinking tests were given to each group of students. Pretests results showed no significant difference in critical thinking abilities between the two groups $(\mathrm{t}=0.37 ; p=>0.05)$. Post test results indicated a statistically significant difference in critical thinking results between the two groups $(\mathrm{t}=5.37 ; p=0.05)$. Those students that participated in the concept map format showed increased critical thinking abilities in the post test as compared to the students who did not participate in the concept map format, indicating a concept mapping can increase critical thinking.

\subsection{Gaps in the Literature}

While an abundant amount of research focuses on active learning, flipped classrooms, and concept mapping, few research studies indicate using concept mapping, active learning strategies, or the flipped classroom increase student success in nursing school. Most published literature on concept mapping focuses on student satisfaction and critical thinking abilities. There was also scarce literature found focusing on the ADN student and concept mapping or the utilizing a flipped classroom in an ADN program.

\section{Statement of the Problem}

According to the NLN (2015) over $30 \%$ of ADN students do not return for their second year of instruction. A study conducted by Griswold (2014), identified some factors influencing the attrition rate of nursing students between the first and second years of instruction. These factors include lack of family support, lack of financial resources, increasing number of hours spent working, decreasing hours spent studying, and the student's perceptions of hostile learning environments. There are an estimated 1.05 million open $\mathrm{RN}$ jobs by the year 2022 (Bureau of Labor Statistics, 2013). In order to meet the demands of the increasing RN workforce an estimated 30,000 students need to graduate with a degree in nursing annually, a 30\% increase in the current graduation rates (Council on Physician and Nurse Supply, 2008). According to the American Association of Colleges of Nursing (AACN, 2015), nursing school application and enrollment rates are up by $2.6 \%$. However, these numbers are not high enough to meet the demand.

With high rates of attrition in nursing programs and the increasing demand for nurses, interventions to aid students in completing nursing programs are essential. The year 2022 is quickly approaching, yet the number of graduating nurses remains relatively stagnant. Without an intervention that proves to increase student success, the nursing deficit could reach a level of crisis impacting the entire healthcare system. There will be an influx of those requiring healthcare interventions as the baby boomers begin to age. This influx in the healthcare seeking population will demand a further increase in the nursing population. Investigation of multiple success strategies in schools of nursing may only be the beginning of the solution to the demand for RNs.

\section{Purpose of the Project}

Within the nursing program of interest, it has been identified there is an attrition problem between the first and second year of the program. Pharmacology I has been identified as the "gatekeeper" course, determining the progression in the nursing program. Among other changes within the program, like increasing admission requirements and the addition of student tutors, it was decided to employ new learning strategies in the Pharmacology I course.

In an effort to explore the issue of high attrition rates within the nursing program at a local community college, specifically in the Pharmacology I course, a quality improvement effort was implemented. This quality improvement effort included implementing a flipped classroom as an instructional intervention in the Pharmacology I course. In the Fall of 2014, all lectures that were historically presented during scheduled classroom time were converted to voice-over PowerPoints and were posted onto the online learning system employed by the college. The students were expected to have viewed the assigned presentations and completed the required reading prior to attending the weekly face-face meetings. During the face-face sessions, students collaboratively worked on creating concept maps relevant to the week's outcomes. These maps guided further discussion on the topics allowing for an active classroom as opposed to the previous format of the traditional, passive classroom. The introduction of this learning strategy allowed time for students to ask questions and address all areas of concerns in the classroom with the instructor present. 
Second semester marks the completion of the first year of study, highlighting the NLN's indication of the highest student attrition rates. This study utilized a retrospective data collection analysis to compare the final examination grades of Level I, second semester ADN students enrolled in Pharmacology I at a rural community college in southwestern Michigan. The independent variable in this study was the introduction of a flipped classroom using concept mapping as the primary activity of the flipped environment. The dependent variable being studied was the final exam scores of the students in the pharmacology course.

Concept mapping has been linked to increased critical thinking and clinical reasoning skills. High levels of critical thinking have been linked to increased student success in nursing school. The introduction of concept mapping in 1984 quickly allowed educators to evaluate students' understanding of concepts and see the linkages the students were able to make between the concepts being studied and the understanding of those concepts (Clayton, 2006). Students have also reported feeling knowledgeable about concepts being studied after designing concept maps (Abel \& Freeze, 2006). Engaging students in learning may increase the number of ADN students that return for their second year of instruction and ultimately increase the much-needed number of RNs in the workforce.

The purpose of this project was to determine if the introduction of a flipped classroom, using voice-over PowerPoints and concept maps as the main components of the flipped environment in the second semester of instruction of ADN students made a difference in student success in the Pharmacology I course (defined as student completing the Pharmacology I course with an overall score of $78 \%$ or greater). The null hypothesis (HO) for this study was: There will be no difference in student unit exam scores between those students enrolled in the traditional classroom setting versus those students enrolled in the flipped classroom setting. In order to accept or reject the $\mathrm{HO}$ a significance level of $95 \%$ or a p-value of $\leq .05$ was implemented. Failing to reject the HO would indicate there is no significant difference in student success when comparing the traditional classroom setting to the flipped classroom setting. Rejecting the HO, would indicate there is a statistical significance in student success when comparing the traditional classroom setting to the flipped classroom setting.

\section{Significance of the Project}

While studies have verified increased student satisfaction with the introduction of active learning, the flipped classroom, and concept mapping, little recorded evidence exists on the impact of student success when employing these methods. In the future, there will have an increased need for RNs in the healthcare system. A solution to the critical nursing shortage is essential. With high attrition rates in ADN programs, student success must be the focus in order to increase the number of nurses entering the workforce. Owing to the fact students have reported greater satisfaction when taking part in active learning, it seems evident this is a good place to begin looking for a solution.

Studies have shown concept mapping, a form of active learning, introduced by Novak and Gowin (1984, as cited in Clayton, 2006), has increased student satisfaction, individual test scores, and knowledge and retention of information. Critical thinking is a benchmark of success on the National Council of State Boards of Nursing Licensure Examination (NCLEX). The National Council of State Boards of Nursing (NCSBN, 2015) states the practice of nursing is one that requires the application of skills and knowledge. In an effort to evaluate the ability of the graduate nurse to apply skills and knowledge, the majority of all the questions on the examination are written at the application or higher level of cognitive ability, thus requiring a complex thought process (NCSBN, 2015). Concept mapping has proven to increase critical thinking skills in the nursing student (Atay \& Karabacak, 2012). The introduction of concept mapping as a means of active learning in the flipped classroom may contribute to increasing knowledge, critical thinking, and student success that will lead to an answer to the future nursing shortage.

The NLN (2015) stated there is an estimated 30\% attrition rate in ADN programs across the nation. Decreasing the attrition rate of nursing students is one of the primary concerns of the nursing education leader and any intervention aimed at increasing the success of nursing students will have great impact on nursing education leadership. Continued research and implementation of successful teaching/learning techniques is needed to enhance nursing curriculum. All nursing curriculum enhancements focusing on increasing student retention and success will ultimately not only enhance the quality of nursing graduates but also the number of graduates, thus leading to an increase supply of graduate nurses. 


\section{Nature, Scope and Limitations of the Project}

\subsection{Nature}

For the purpose of this study, the researcher conducted a quantitative non-experimental retrospective post-intervention data collection design comparing traditional versus flipped classroom final exam scores. A quantitative approach was used to compare student success rates between the two groups. Data from multiple cohorts were collected and compared to provide statistical significance and reliable results.

As part of an ongoing quality improvement effort focused at student retention, a flipped classroom method was introduced into the Pharmacology I course in the Fall of 2015. The flipped classroom consisted of Voice-over PowerPoints posted to the LMS and active learning techniques like concept mapping were employed during face-to-face class time. This study aimed to compare student success rates of the students that were enrolled in the traditional classroom to those students in the flipped classroom. Focusing on student success, the study looked at student final examination scores over the span of six semesters. All students in the nursing program are required to take this course in the second semester of their first year of instruction in the school of nursing. There were two groups in the study, each consisting of three cohorts of data, totaling six cohorts. Final exam scores were retrospectively gathered from the institution's learning management system (LMS), Moodle $\odot$ for those students who have completed the course within the specified timeframe. Group one consisted of those cohorts having taken the traditional Pharmacology I course and group two consisted of those cohorts having taken the flipped classroom course.

The flipped classroom included voice-over PowerPoints that were posted on the LMS. Pre-class reading assignments and the utilization of concept mapping as the primary in-class activity. The dependent variable in this retrospective study was the final exam scores with the introduction of the flipped classroom and concept mapping. Student success was defined as the student passing the Pharmacology I final examination with at least a $78 \%$.

\subsection{Scope}

Exclusion criteria consist of any data from a student who has taken the Pharmacology I course more than one time. Hearing the material and taking part in the course more than once may alter the reliability of their scores. Therefore, this data was not be collected by the proxy. Only data from those students in the nursing program and taking Pharmacology I was considered for the study. All other student data within the organization was excluded from the study.

Inclusion criteria for the study included all final exam data from students enrolled in the Pharmacology I course from September 2014 - December 2016. The retrospective data analysis included six 14-week semesters of data. All students within the data cohorts completed the Pharmacology I course prior to the gathering of any data. All student cohorts had the same instructor and taken the same final exam. Differences or lack thereof in student success rates were compared between group one and group two. After completion of the data analysis and result gathering, a summary of the findings was presented to the Dean of the School of Nursing and Health Services and the Vice President of Instruction at the college for their review and is available for public view.

\subsection{Limitations}

A sample of student final exam scores was utilized in the study. This sample will only include data from six cohorts of students. This sample may not have been representative of the entire population of ADN students across the United Sates. It was also recognized that a convenience sample may also be bias. There was a potential for a small sample of data available for extraction, which may also have impacted the results of the study. There was no way to determine if the students completed the lectures or reading assignments prior to class time. Lack of pre-class viewing of the lecture may have led to altered results of the study. The researcher was not present to observe study habits of the students outside of the classroom. Failure to study outside of the classroom may have rendered some of the lower test results. There were six different sets of data studied through the course of this research. Exam scores of the three groups were analyzed based on a traditional lecture setting teaching method while the other three were analyzed based on the flipped classroom setting. The researcher was not be to determine how the traditional students would perform in the flipped classroom and vice versa in those students that underwent the intervention of the flipped classroom.

\subsection{Delimitations}

In this school of nursing, it has been found most students that are not successful are from the first year, second semester of instruction. Pharmacology I is the course that is most linked to increased attrition rates in the second semester of instruction. Because Pharmacology I is labeled the "gatekeeper" course, only data from this course 
was considered in the data extraction. Final exam scores from the selected cohorts was extracted from the leaning management system by a proxy. Any data from students enrolled in semesters I, III, and IV of the programs was not considered in this study. This research did not aim to consider data from students outside of the school of nursing. Final exam data was not extracted from those students having taken the course more than once. Hearing the material and taking part in the course more than once may have altered the reliability of the data. The phenomenon that was considered in this study was the introduction of flipped classroom with concept mapping. Any other intervention variable that arose during research were not considered as part of the data analysis.

\section{Theoretical Framework}

Ausubel (1968) introduced his theory of assimilation in the book, Educational Psychology: A Cognitive View. In this theory, Ausubel differentiates between rote memorization and meaningful learning. Rote memorization is the act of simply memorizing facts and pieces of information without having to think about or contribute meaning to the memorized information. Meaningful learning turns the rote memorization into a process of growth and expansion of information. It gives meaning to the memorized data (Ausubel, 1968). Although several methods of instruction have been attempted to be integrated into education, the primary means of information delivery is that of the instructor standing at the front of the room and spewing facts to the not so ever intently listening students. Delivering information in this fashion increases the value of memorization or rote learning the students already possess. Because the instructor is spitting out facts in a very quick and precise manner (in order to cover all the material) it is assumed by the student, the facts are important to memorize. What fails to happen in this traditional classroom setting is the assimilation of the presented material.

Assimilation of material is the ability to give meaning (or to meaningfully learn) newly presented information. In simple terms, assimilation is placing meaning to new information by relating or reducing the new information into already established ideas (Ausubel, 1968). Assimilation is one of Ausubel's meaningful learning strategies that helps aid in the retention and availability of information. To provide an example of assimilation in the simplest view, imagine an asthmatic patient having an asthma attack. To the student, an asthma attack is characterized by dyspnea, wheezing, and lack of oxygen exchange (the facts given to them by the instructor at the front of the room.) To help the student assimilate this information, it could be presented by using a balloon. The balloon would represent the lungs (a vessel for holding air). In asthma, there is an outflow of air problem. Students already understand what will happen when they stretch the mouth of the balloon and begin to slowly let air out; there is a whistling sound. Explaining to the student the balloon with the pinched mouth represents asthmatic lungs during an attack helps them to assimilate wheezing during an asthma attack. The already known information of slowly letting the air out of a balloon has now been associated with an asthmatics lung and the student can quickly recall and troubleshoot (critically think) what needs to be done to stop the wheezing, dyspnea, and lack of oxygen exchange (open the mouth of the balloon).

In nursing education, it is essential for students to engage in meaningful learning rather than rote memorization. Concept mapping is a tool that can be used to allow students to begin turning memorized facts into meaningful information (Novak \& Gowin, 1984). With the guidance of Ausubel's theory of assimilation, the flipped classroom and concept mapping was used to create assimilation of information presented in Pharmacology I at a local community college. The ADN students were introduced to the flipped classroom and concept mapping during scheduled class time. Prior to the entrance into class, the students were expected to have listened to the provided online PowerPoint presentations, read the assigned text material, and taken a quiz on the material. The purpose of the concept mapping in class was to associate or assimilate the learned knowledge from the PowerPoints, reading, and quizzes into meaningful learning that will be retained and later reflected in the form of in class exams and later the state mandated boards to obtain the title of RN. 


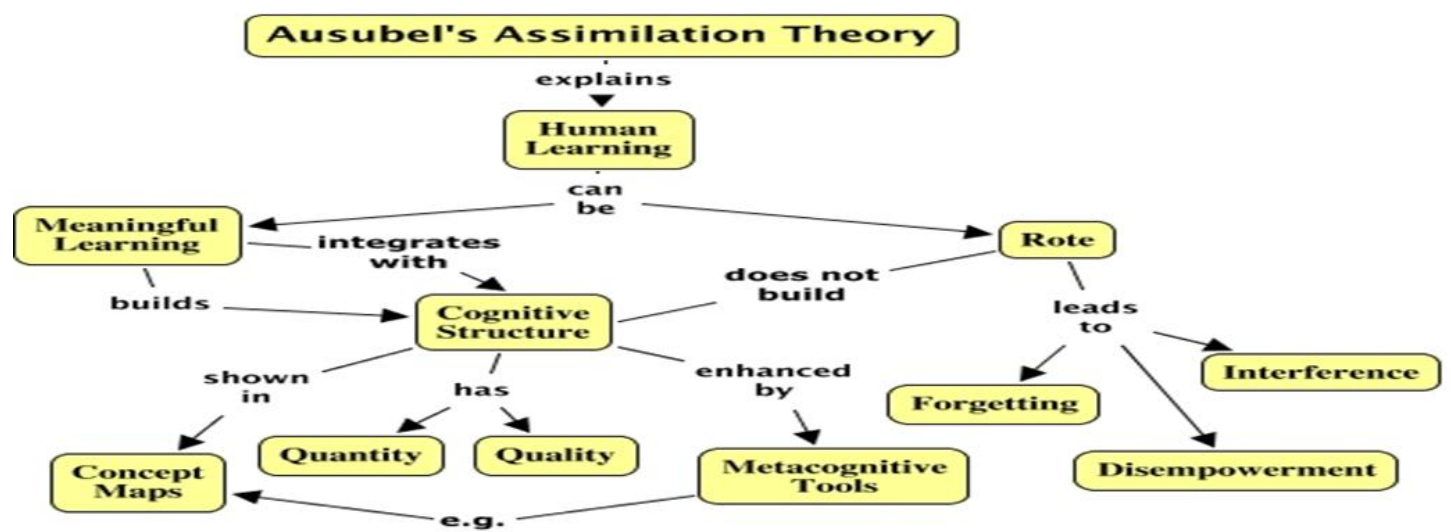

Figure 1. IHMC. (2014-2015). Q-27 Ausubel's assimilation theory

This research directly correlated to Ausubel's Assimilation Theory (Figure 1) in the following ways:

- Human learning: The act of humans learning new information (enrollment in the Pharmacology I course).

- Rote learning: Memorization of new material without assigning meaning to the information (Ausubel, 1968). This is associated with the online PowerPoints and reading material. Rote learning then leads to information interference because there is no association of meaning to the information being obtained. Without the associating meaning to the information, the student quickly forgets the learned information which then leads to feelings of disempowerment when they are unsuccessful in the course.

- Meaningful learning: Giving meaning to the new information by assimilating the information with preexisting knowledge (Ausubel 1968). This was addressed in the classroom setting by integrating the pre-class PowerPoints, reading, and quizzing with active learning strategies.

- Cognitive structure: The basic mental processes people use to make sense of information (Gardner, 2007). Concept mapping was the cognitive structure (active learning technique) in the proposed project. Quality and Quantity - refers the learned information. With the use of concept mapping as a tool for meaningful learning, there may have been an increase quality and quantity of learned information. This in turn may have led to greater student success.

- Metacognitive tools: Involves actively thinking about what is known, what is not known, and how to get better at knowing and applying what is known (Instructional Design Fusions, 2010). The construction of concept maps may have led the students to think about what information was understood and what information was not understood. Areas that need more student attention did arise within the classroom setting and gave the students a guide of how to focus their studies.

\section{Definition of Terms}

Student success: Student success is defined as the student passing the Pharmacology I final examination with at least a $78 \%$.

Concept map: A concept map is a visual tool used to identify and organize relationships between ideas and concepts (Novak and Canas, n.d.). These relationships are established using lines to connect each idea or concept to one another. The main concept is at the center of the map.

Concept: A concept is an abstract or generic idea about the subject matter being studied (Merriam-Webster's online dictionary, 2015). For the purpose of this study, the main concept in the concept map was typically be a specific drug classification.

Flipped classroom: In this research, a flipped classroom consisted of all the traditional lectures posted on the online learning system in the form of voice-over PowerPoints. The students were expected to view/listen these lectures prior to entering the classroom. In-class time was spent collaboratively constructing and discussing concept maps over the assigned weekly material. The instructor served as a facilitator and guide of the construction and discussion, but not the leader in the construction or the discussion of the concepts.

Nurse: For the purpose of this research, the term nurse refers to anyone who has successfully passed the mandated licensing exam and holds an active license as a RN. 


\section{Summary}

Traditional methods of classroom teaching are slowly beginning to fade from institutions of higher education as the population of students is demanding to be more engaged in the learning process. The introduction of active learning in the form of a flipped classroom and concept mapping is one way to engage the nursing student in the classroom. Student engagement may impact the critical thinking abilities in the students which may in turn increase student success in the classroom. This study focused on student success in a Pharmacology I course that utilized a flipped classroom and concept mapping. The intent of the study to determine if there is a statistically significant difference in student success (as defined as passing the final examination with at least a 78\%) with the introduction of a flipped classroom and concept mapping.

\section{Methods}

The purpose of this study was to determine if the introduction of a flipped classroom, using concept mapping as the main component of the flipped environment in the second semester of instruction of ADN students made a difference in student success (defined as student pass rate of at least $78 \%$ in the course). Ausubel's theory of assimilation was used to guide this quantitative retrospective study. Approval was sought from university's Institutional Review Board (IRB) and the IRB from the school involved in the study prior to any data collection or analysis. Exam scores were gathered from students enrolled in a Pharmacology course ranging from September 2014 - December 2016. The final exam scores were analyzed to determine if there was a difference in scores between the students enrolled in the traditional class (September 2014 - May 2015) and the students enrolled in the flipped classroom (September 2015 - December 2016).

\subsection{Project Design}

The purpose of this study was to determine if the introduction of a flipped classroom, using concept mapping as the main component of the flipped environment in the second semester of instruction of ADN students made a difference in student success (defined as student pass rate of at least $78 \%$ in the course). Ausubel's theory of assimilation was used to guide this retrospective non-experimental study.

There were six cohorts of student data used in this study. Upon the approval from both the IRB at university and the institution of proposed research, data was extracted from the learning management system by a proxy. The proxy extracted only final exam scores and the cohort information from the records. No information was extracted until the completion of each semester when all grades had been submitted to the college. The proxy randomly assigned numbers to the student data collected and record this on an excel spreadsheet. Once the data was recorded on the excel spreadsheet, the proxy gave the spreadsheet to the researcher. At that time, IBM SPSS software was used to create a codebook. Data was analyzed using independent $t$-test to compare the final exam scores of the students that were enrolled in the traditional classroom versus the final exam scores of the students enrolled in the flipped classroom. The design allowed the research question to be answered by comparing data from cohorts enrolled in the traditional classroom and cohorts enrolled in the flipped classroom. The independent t-test was used to compare the means of two independent groups (traditional and flipped cohorts).

\subsection{Sample and Setting}

All the students enrolled in the nursing program must take the Pharmacology I course in the second semester of the program. Therefore, the study used data collected from 176 that had been enrolled in the course between September 2014 and December 2016. G*Power 3.1 was used to determine the adequate number of data records needed to validate this study. An effect size of .5 determined a sample of $n=210$ data records were needed for this study (Faul, Erdfelder, Buchner \& Lang, 2009). Of the 210 data records, 105 were from those students enrolled in the traditional classroom and 105 data records were from those enrolled in the flipped classroom. This power analysis included a medium effect size of 0.5 which assumes the probability of a Type I error of $\alpha$ err 0.05 , and the probability of a Type II error of $1-\beta$ err 0.95 .

\subsection{Exclusion Criteria}

Exclusion criteria consisted of data from students retaking the course at the time of the study or have taken the course more than one time prior to the initiation of the intervention. Hearing the material and taking part in the course more than once may alter the reliability of their scores. Therefore, data from these students was not considered for this study. All other student final exam grades were included.

\subsection{Setting}

This study was conducted at a local community college located in southwestern Michigan. The college was opened in 1964 and is very established and reputable within the community and surrounding areas. The college 
is in a rural setting and comprises of a very diverse student population. Per credit tuition is as follows: $\$ 115.25$ for in-district students, $\$ 150.25$ for in-state students, and $\$ 164.00$ for out of state students. There is dormitory housing on campus that houses 250 students, however, most of the student population commute to the college for classes. Average yearly cost to stay in on campus dorms is $\$ 7,802$.

Along with offering a multitude of certificate and associate degree options, the college offers an associate degree in nursing $(\mathrm{ADN})$. The nursing department is housed within the School of Nursing and Health Services (SONAHS). Currently SONAHS offers certificates in Emergency Medical Technology, Nursing Assistant, and phlebotomy. SONAHS offers associated degree programs in nursing (ADN), health information technology, and medical assisting. The average student population in SONAHS is 245 students and the average student population in the nursing program is 149 students (divided between four semesters). Of the 149 nursing population approximately 30 students are enrolled in Pharmacology I each semester

The student population of the nursing program is diverse and includes but is not limited to male and female students, students from multiple income brackets, and ethnicities, and English as a Second Language students (ESL). Student ages vary from 18 years old $-50+$ years old. The program is designed to be completed over four semesters, however, students have the option to attend the program on a part-time basis. All students are highly encouraged to complete the program within six semesters. The program accepts 40 students twice a year (Fall and Spring admissions). Acceptance in the program is contingent on meeting minimal requirements set by the program. These include completion of five prerequisite courses; freshman English, fundamentals of chemistry, basic human anatomy, introduction to algebra and general psychology. Students must maintain a prerequisite grade point average (GPA) of at least 3.0. Students are chosen based on an 8-point system, the 40 students with highest points are accepted into the program. Points are awarded based on the prerequisite GPAs and the overall school GPA. Four points are possible for both the prerequisite GPA and the overall college GPA (totaling 8 possible points). Other requirements for admission include a current physical exam (within one year), proof of residency, and high school transcript or proof of general education diploma (GED).

\subsection{Data Collection Tool}

All students enrolled in both the traditional and flipped classroom took the same final exam. The final exam consisted of 100 questions. There were multiple question formats within the exam which included multiple choice, alternative format, and dosage calculations. The final exam was comprehensive, encompassing aspects of all material covered over the 14-week semester course. Scores from each student meeting the criteria was extracted and recorded. No other demographic data was extracted.

The instrument used in this study was an Excel spreadsheet. Results of the final examination scores were extracted from the online learning management system by a proxy. The proxy randomly assigned each exam grade a number, recorded the cohort of the student and the exam scores of the student. Assigning numbers to the exam scores and de-identifying the records ensured student confidentiality and anonymity, thus abiding by the National Institutes of health (NIH) and Family Educational Rights Privacy Act (FERPA) regulations. Retrospective data was collected at the completion of each semester. The data collection tool (Excel spreadsheet) used was designed specifically for this study and served only to record retrospective data.

\subsection{Data Collection}

Data were collected retrospectively by the proxy from the online learning system in place at the study site, Moodle $\odot$. Moodle $\odot$ is a customizable learning platform designed to provide educators, administrators and learners with personalized learning environment (Moodle, 2016). The final exam scores were collected from the online grade book provided within the Moodle $(\odot$ platform and recorded on the data collection tool by the proxy. Student exam scores were initially recorded in the grade book by the instructor once grading and test analyzation is performed. No student names or demographics were collected in this study.

The same instructor taught Pharmacology I to both groups. In the traditional classroom, PowerPoints were utilized as part of an instructor led lecture. In class lecture was the sole means of content delivery. The flipped classroom also utilized PowerPoint, however, these were posted online and had a voice lecture attached to the presentations. Students were responsible for accessing and listening to the PowerPoints outside of class time as well as completing pre-class reading assignments. During class time, students were placed in groups to complete concept maps on the assigned weekly material. The main concept (drug classification and mechanism of action) was placed in the center of the map, fingers of the map included: drug names, side effects, adverse drug reactions, expected drug reactions, drug/food/environmental interactions, special considerations, nursing interventions, and patient education. The maps were then discussed in class with the instructor serving to keep students focused, and answer any questions the students had on the weekly concepts. Students in the flipped classroom were 
instructed of the expectations on the first day of class. The course was accessed through LMS and projected to the class. The instructor walked through how to access the PowerPoints and gave the students a required reading and PowerPoint viewing schedule. A concept map was also constructed on the first day of class to demonstrate the expectations of the activity. The instructor assumed the students came into class prepared to participate in class activities. There was no means to measure student preparation prior to class.

Both classroom settings took the same final exam. All data was collected and de-identified by the department's administrative assistant who served as a proxy. Data was only passed on to the researcher in the form of an excel spreadsheet for data coding and analysis. Because this is a retrospective data analysis and involves working with data only, no informed consent was required for the completion of this study. Permission to access the data was obtained from the Dean of the School of Nursing and Health Services at the college.

\subsection{Data Analysis Methods}

Once all data was collected and recorded on the data collection tool, the information was then transferred into a codebook using IBM SPSS software. Variables recorded in the codebook included participant number, participant cohort, and participant individual unit exam scores. Bivariate and descriptive statistics were used in the data analysis through the use of an independent t-test. Descriptive statistics were gathered on the unit exam scores and raw data was organized into two groups: those enrolled in the traditional classroom environment and those enrolled in the flipped classroom environment. Upon completion of the data collection process, the unit exam scores of the traditional classroom setting and the flipped classroom setting were compared using a two-tailed independent $t$-test with a significance level of 0.05 for analysis, indicating there is a $5 \%$ chance the null hypothesis was falsely rejected. The independent t-test is used when comparing the mean scores of two independent groups (Pallant, 2013). In this study, those students who were enrolled in the traditional classroom setting and those students enrolled in the flipped classroom are independent from one another, thus using an independent t-test for analysis is the appropriate test for this study. This study aimed to determine if there was a difference in student success rates after the implementation of a quality improvement initiative. Therefore, a two-tailed test was used to look at the differences in both directions (increased or decreased student success).

\subsection{Data Management Methods}

All raw and coded data was recorded on a password protected flash drive and handled only by the researcher. All statistical analysis was also stored on this flash drive. This flash drive was kept in a locked safe at the researcher's home when not being used. The flash drive will be stored and maintained in the researcher's locked safe for the duration of five years after the completion of the study. After the duration of five years, the flash drive will be erased.

\subsection{Ethical Considerations}

Because this was a retrospective study and only involved collecting and analyzing data, no informed consent was needed to proceed with the research. No data was collected until all cohorts of interest had completed the course and presented no risk to the students. Permission from both university's IRB and the IRB at the school was obtained prior to the initiation of data collection. Confidentiality of student information was maintained by the proxy's de-identification of student data prior to data analysis.

This study was deemed to be one of minimal risk to participants and the probability and magnitude of harm or discomfort anticipated during this project was not greater than any ordinarily encountered in daily life, or during performance of routine physical or psychological examinations or tests.

\subsection{Internal and External Validity}

Final exam questions were retrieved from the textbook publisher's instructor resources website as well as from multiple published NCLEX review textbooks. The exams given to the students were identical. The data collection tool was designed specifically for this study and collected only information on student unit exam scores and type of classroom setting the student was enrolled.

Threats to internal validity include the instructors comfort level with the course material as well as the instructors comfort level in the flipped classroom setting. As the instructor's comfort level with the material and setting increased, specific content delivery may have been added or eliminated, thus changing the amount of information delivered to the different cohorts of students

Threats to external validity include being able to generalize the collected information based on the setting. A rural community college setting, as used in this study, may not have obtained the same results as studied performed at the university level and therefore, results may not be deemed appropriate to generalize. There may 
also be an interaction between the setting and the intervention. The quality improvement effort to increase student success at a local community college may not be applicable to the needs of students at a four-year university setting and the study may need to be replicated in multiple settings to determine external validity.

\subsection{Summary}

This DNP project used a quantitative retrospective design to examine the results of student success rates in the traditional classroom setting and the flipped classroom setting. Independent $t$-test analysis was performed to determine if there is a statistically significant difference in student success when comparing the traditional classroom setting to the flipped classroom setting, using a p-value of $\leq .05$ to determine significance. The project compared unit exam scores as a means of comparison in this study.

\section{Results and Discussion of Findings}

The purpose of this study was to determine if a flipped classroom using concept mapping as the primary active learning tool made a difference in student success rates in the Pharmacology I course by using a retrospective data analysis. The research question for this study was: Did the introduction of the active, flipped classroom make a difference in student success rates when compared to the student success rates in the traditional class room in a pharmacology course. The independent variable in this study was the introduction of a flipped classroom using concept mapping as the primary activity of the flipped environment. The dependent variable being studied was the final exam scores of the students in the pharmacology course. This section will focus on the results of the data analysis, major findings of the study, implications to nursing practice, and recommendations for future studies.

\subsection{Summary of Sample and Setting Characteristics}

This retrospective study took place at a local community college in Southwestern Michigan. Within the college is a striving nursing program aiming to increase student retention and success. As part of the effort to increase student success in the nursing program, a quality improvement project was initiated in the Pharmacology I course. This course often serves as the "gatekeeper" course for the nursing program. The typical enrollment lies between 20-38 students. In order to progress through the nursing program, all students are required to take the Pharmacology I course in their second semester of the nursing program. The target population consisted of all students enrolled in the 14-week Pharmacology I course from Spring 2014 to Fall 2016. For the purpose of the quality improvement and the data analysis, student success is defined as passing the comprehensive final examination with a score of $78 \%$ or higher.

Between the Spring 2014 semester and the Fall 2016 semester, there were a total of 176 comprehensive final examination scores for analysis. After applying the exclusion criteria (those repeating the course), 169 final examination scores were analyzed. No other demographic data was collected in this study. Traditional cohorts include Spring 2014 - Spring 2015. Flipped classroom cohorts included Fall 2015 - Fall 2016. Figure 2 represents the number of data points available versus. The number of data points that were excluded in the study.

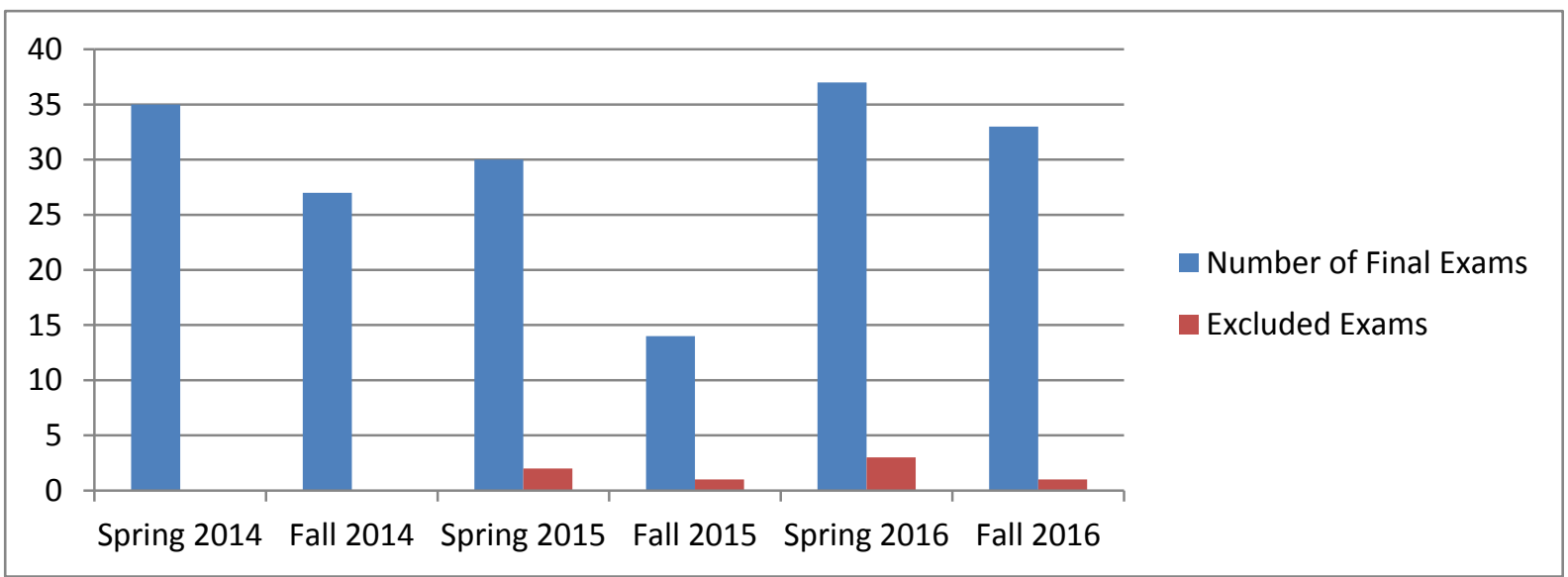

Figure 2. Demographic per cohort

This graph indicates the number of final examinations that were taken each semester and the number of final examinations excluded from data analysis. 


\subsection{Summary of Methods and Procedures}

To determine if the flipped classroom (Group 2) and concept mapping made a difference in student success as compared to the traditional classroom (Group 1), the means of the final exam between both groups were compared. A Q-Q plot demonstrated a normal distribution of data with a few outliers (see Figures 3 and 4).

Levene's test for examining the equality of variance was performed (see Table 2). The columns labeled "Levene's Test for Equality of Variances" shows whether an assumption of the t-test has been met. The t-test assumes that the variability of each group is approximately equal. If that assumption isn't met, then a special form of the t-test should be used. In the table, the column labeled "Sig." under the heading "Levene's Test for Equality of Variances," the significance (p value) of Levene's test is .129. If this value is less than or equal to the $\alpha$ level for the test (.05), then we can reject the null hypothesis that the variability of the two groups is equal, implying that the variances are unequal. If the $p$ value is less than or equal to the $\alpha$ level, then we use the bottom row of the output (the row labeled "Equal variances not assumed.") If the p value is greater than the $\alpha$ level, then we should use the middle row of the output (the row labeled "Equal variances assumed.") In this analysis, .129 is larger than $\alpha$, so we will assume that the variances are equal, and we will use the middle row of the output. Therefore, using an independent $\mathrm{t}$-test is the appropriate statistical analysis for this study (See Table 2).

Table 2. Levene's Test

This table represents the results of the Levene's test for equality of variances and t-test equality of means analysis.

\begin{tabular}{|c|c|c|c|c|c|c|c|c|c|c|}
\hline & \multicolumn{3}{|c|}{$\begin{array}{c}\text { Levene's Test for Equality } \\
\text { of Variances }\end{array}$} & \multicolumn{5}{|c|}{ t-test for Equality of Means } & \multicolumn{2}{|c|}{$\begin{array}{l}95 \% \text { Confidence } \\
\text { Interval of the } \\
\text { Difference }\end{array}$} \\
\hline \multirow{3}{*}{$\begin{array}{l}\text { Final } \\
\text { Exam } \\
\text { Score }\end{array}$} & & $\mathrm{F}$ & Sig & $\mathrm{t}$ & $\mathrm{df}$ & $\begin{array}{c}\text { Sig. } \\
\text { (2-tailed) }\end{array}$ & $\begin{array}{c}\text { Mean } \\
\text { Difference }\end{array}$ & $\begin{array}{l}\text { Std. Error } \\
\text { Difference }\end{array}$ & Lower & Upper \\
\hline & $\begin{array}{l}\text { Equal } \\
\text { variances } \\
\text { assumed }\end{array}$ & 2.328 & .129 & 1.48 & 167 & .139 & 1.6087 & 1.0814 & -.5262 & 3.7437 \\
\hline & $\begin{array}{l}\text { Equal } \\
\text { variances } \\
\text { not assumed }\end{array}$ & & & 1.46 & 149.31 & .145 & 1.6087 & 1.0968 & -.5585 & 3.7760 \\
\hline
\end{tabular}

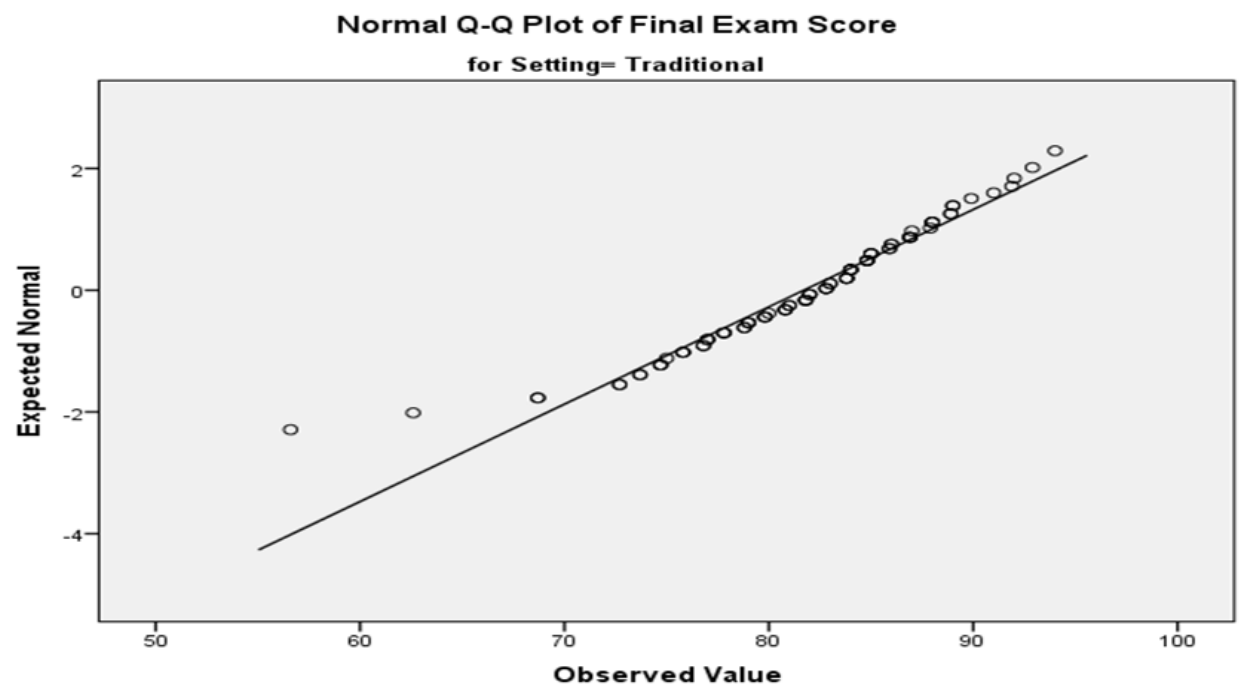

Figure 3. Distribution of exam scores

This graph indicates the distribution of final examination scores in the traditional classroom setting. 


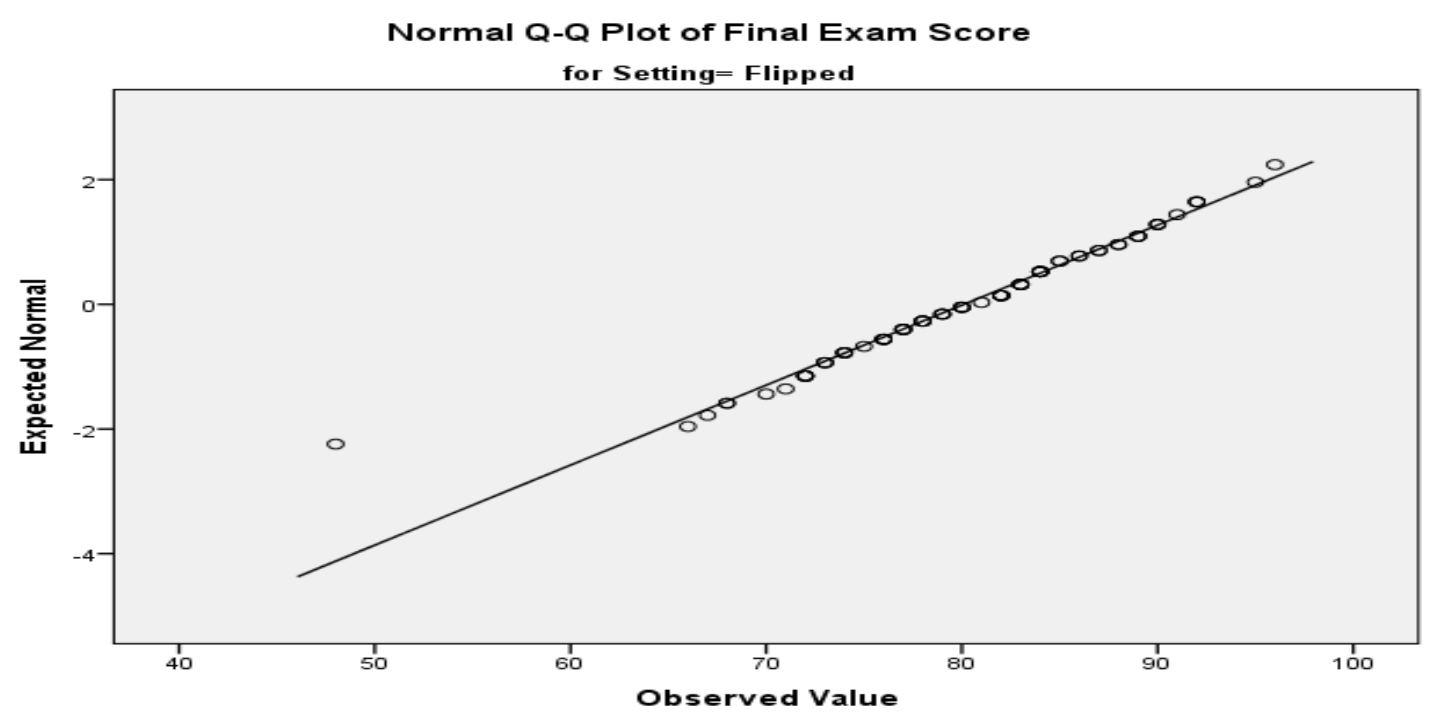

Figure 4. Distribution of exam scores

This graph indicates the distribution of final examination scores in the flipped classroom setting.

An independent sample t-test was used to compare final exam scores for those enrolled in the traditional classroom setting $(\mathrm{N}=90)$ and those enrolled in the flipped classroom setting $(\mathrm{N}=79)$. In an effort to decrease the chance of a Type I error (rejecting the $\mathrm{H}_{\mathrm{O}}$ when $\mathrm{H}_{\mathrm{O}}$ is actually true), a two-tailed 5\% significance level was chosen for data analysis (Pallant, 2013). Two-tailed testing evaluated for differences in multiple directions, assuming that an extreme score can occur in either tail (Burns \& Grove, 2009). Specific data analysis of interest in this study included: the mean (M), indicating the average exam score; the mode, indicating the most frequently appearing score; the standard deviation (SD), indicating the average differences in scores; the $t$ value, indicating the size of the difference between the two group means; and the probability of the event occurring (p). Also, of interest in this analysis was calculating the mean difference or difference in means between the two groups. The confidence level interval indicates the mean will be repeated in $95 \%$ of all repeated studies. The eta, or size of differences between the two groups was also calculated in this study. Descriptive statistics for both classroom settings are available in Table 3.

Table 3. Descriptive statistics

This table represents the descriptive statistics for both the traditional and flipped classroom settings.

\begin{tabular}{llllll}
\hline Group & $\mathrm{N}$ & Mean Score & Mode Score & SD & Std. Error Mean \\
\hline Traditional Classroom & 90 & $81.7 \%$ & 84 & 0.46 & .6592 \\
Flipped Classroom & 79 & $80.3 \%$ & 84 & 0.62 & .8766 \\
\hline
\end{tabular}

\subsection{Major Findings}

The t-test failed to reveal a statistically reliable difference between the mean final examination score in the traditional $(\mathrm{M}=81.7, \mathrm{SD}=6.3)$ and in the flipped classroom setting $(\mathrm{M}=80.1, \mathrm{SD}=7.8), \mathrm{t}(135)=1.39, \mathrm{p}=.14$. The two tailed box plot of the two groups mean final examination scores shown in figure 5 indicated a low likelihood of a significant difference in mean scores or variation between the two groups. Data was assumed to be reasonably normally distributed based on the Q-Q plot graphs in Figure 3 and Figure 4. A 95\% two-tailed confidence interval for the difference in means was $(-.55,-3.8)$. With $\mathrm{p}=0.14$, the null hypothesis that there is no significant difference in final examination mean scores between the traditional and flipped classroom cannot be rejected. 


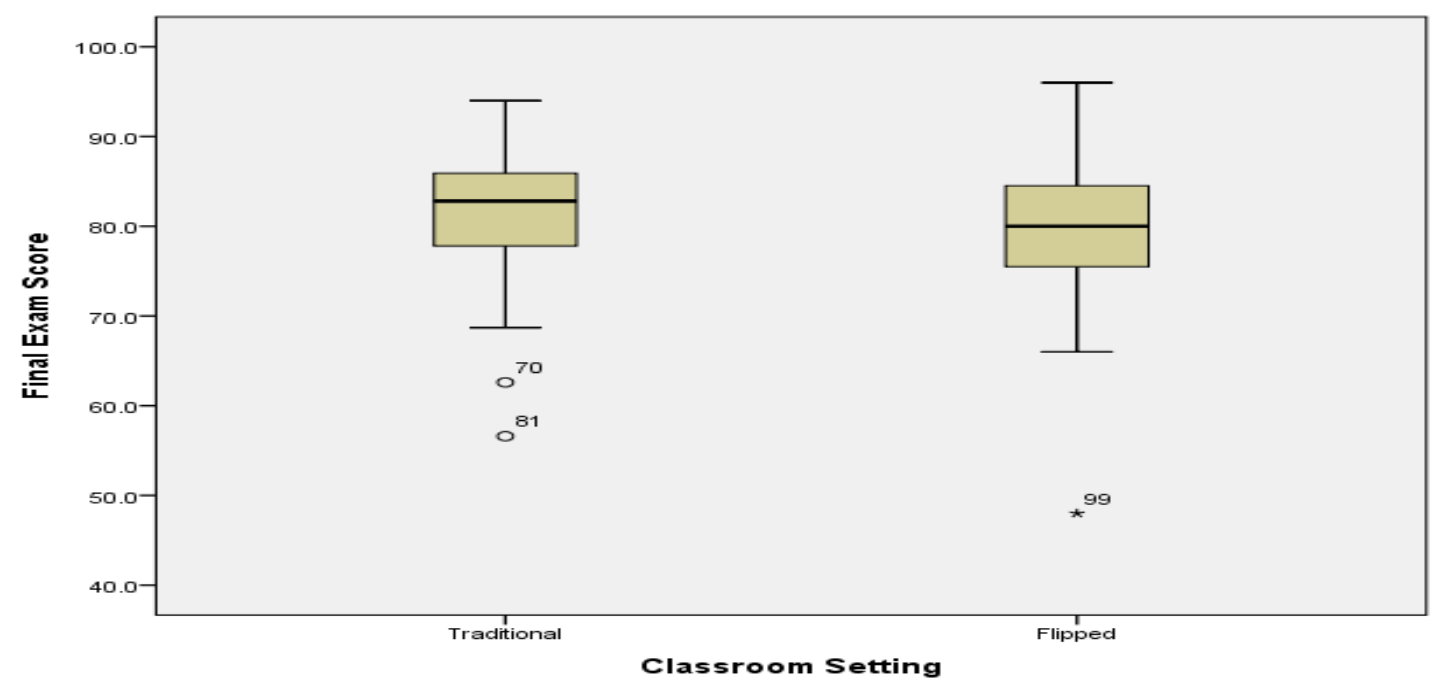

Figure 5. Box plot of means

This figure represents the distribution of the final examination scores in the traditional and flipped classrooms.

\subsection{Discussion of Major Findings}

When analyzing the data for this study, it was noted the Fall 2016 (flipped classroom setting) semester had a concerning number of failing grades on the final examination. The percentage of failing grades in that semester was higher $(56 \%)$ than the average percentage of failing in all other semesters (failing final exam scores than any of the other semesters, traditional or flipped settings (27.8\% and $23.4 \%$ respectively). The researcher was curious if the results of the data analysis would differ if this particular semester was not included in the data analysis. The results of the independent sample t-test eliminating the Fall 2016 semester also showed no statistically significant differences in means of the traditional classroom $(\mathrm{M}=1.26, \mathrm{SD}=.439, \alpha=.05)$ and scores in the flipped classroom $(\mathrm{M}=1.23, \mathrm{SD}=.425), \mathrm{t}=(99)=.34, \mathrm{p}=.73$, two-tailed. A $95 \%$ two-tailed confidence interval for the difference in means was $(-.13, .18)$. With $\alpha=0.05$, the null hypothesis that there was still no significant difference in final examination mean scores between the traditional and flipped classroom cannot be rejected. Although there were no statistically significant differences in the means between the two groups, the elimination of the Fall 2016 semester did show an increase in the percentage of passing grades on the comprehensive final examination for those students enrolled in the flipped classroom (76.6\%) setting as compared to those enrolled in the traditional classroom setting $(72.2 \%)$.

The results of this study are comparable to the results of previous studies completed on the traditional versus flipped classroom by Murray, McCallum, and Petrosino's (2014) and Harrington et al. (2015). Murray, McCallum, and Petrosino's (2014) study consisted of 53 physical therapy students. The results of their study revealed that although the cohort of students that participated in the flipped classroom had slightly higher examination scores, the difference was not statistically significant when comparing the examination scores to those students enrolled in the traditional classroom setting $(\mathrm{p}=.19)$. Similar results were reported in the study completed by Harrington et al. (2015). No significant differences were revealed when comparing examination and quiz scores between a traditionally led classroom and a flipped classroom in Harrington et al.'s study. However, the study did reveal the examination and quiz scores of those students enrolled in the flipped classroom were slightly above those enrolled in the traditional classroom. Focusing on a pharmacology course, Geist et al. (2015), noted higher unit examination scores in those students involved in the flipped classroom setting than the students in the traditional classroom. However, when comparing final examination scores of the students in the traditional and flipped classroom, there was not a significant difference in the scores between the two groups. Before the inclusion of the Fall 2016 cohort in the original study, the percentage of students in the flipped classroom setting with final examination scores $78 \%$ or above was slightly higher than the percentage of final examination scores of the students enrolled in the traditional classroom setting. The average final examination score for those students enrolled in the traditional classroom was $81.7 \%$ and the average final examination score for those students enrolled in the flipped classroom was $80.3 \%$. If the Fall 2016 cohort (average final examination score of 76.8) is eliminated from the study, the average final examination grade for 
the students in the flipped classroom was an $82.9 \%$; which is slightly above the mean of $81.7 \%$ in the traditional classroom. However, the data did not reveal a significant difference in student success rates (82.9\%).

Although significant differences in success rates between the traditional and flipped classroom were not revealed, the increased percentage of student success in the flipped classroom partially supported Ausubel's theory of assimilation. Giving meaning to the information presented to the student increases the student's retention of the information (Ausubel, 1968). By utilizing Bergmann and Sam's (2012) flipped classroom concept and presenting active learning activities in the classroom rather than conducting a passive learning experience, the student's final examination grades in the flipped classroom setting showed a slight increase in success than of those students enrolled in the traditional classroom. Allowing students to actively participate in concept mapping while in the classroom helped them assimilate the knowledge, they gained from the reading assignments and PowerPoints viewed prior to class as indicated by the higher final examination scores of the students enrolled in the flipped classroom (eliminating Fall 2016 from the study).

\section{Implications for Nursing Practice}

Although the findings in this study did not demonstrate any statistical significance, there were slight increases in final examination scores of the students that were enrolled in the flipped classroom as compared to the students enrolled in the flipped classroom. Based on this information, continuing to utilize and improve the flipped classroom experience may continue to increase student success rates in nursing education. This is significant to nursing practice because by the year 2020, there will be an excess of 1.05 million job postings for registered nurses in the United States (Bureau of Labor Statistics, 2012). Efforts dealing with the nursing shortage should start in the nursing programs. Initiatives to increase student success rates in the classroom are the keys to filling the 1.05 million job openings.

From the standpoint of nursing education as a community college level, small increases in student success rates may have large implications on future enrollment and future funding for the college and the nursing program. Continual increases in student success at the community college displays a program that strives on continued quality improvement and achieving student success. This in turn may attract a larger number of future students interested in the community college nursing program. The improved student retention rates also positively impact the funds appropriated to the college by the State of Michigan.

State funding appropriations in Michigan is based on a formula. According to the formula funding, the institution receives funding-based meeting specific factor criteria. The fewer factors an institution is able to meet, the less funding the institution will receive. The State of Michigan uses six criteria when appropriating funds: undergraduate degree completions in critical skills, research and development expenditures, six-year graduation rates, total degree completions, institutional support expenditures, and percentage of students receiving Pell Grants. By utilizing the flipped classroom and active learning techniques four of the six criteria may show improvement: undergraduate degree completions in critical skills, research and development expenditures, six-year graduation rates and total degree completions. Increases in these four may ultimately increase the amount of state appropriated funds allocated to the institution.

\section{Recommendations for Future Studies}

In order to research this topic further, the researcher recommends the following: increase the number of data available by expanding the research to multiple test sites and utilizing faculty who has experience in the flipped classroom teaching. Different active learning activities should also be explored. The students in this study became disengaged in the concept mapping activities after participating in several sessions. It is also very important that completing pre-class quizzes and activities be required. These activities would help prepare the students for in-class active learning. This study was completed using a limited data. Increasing the data available for the study would not only strengthen the finding of the study but also allow for generalizing the results.

Another recommendation based on this study is to either engage faculty members with experience in the flipped classroom or ensure the faculty member participating in the flipped classroom has undergone some type of formal training on the flipped classroom. As indicated by Harrington et al. (2015), faculty experience and proper preparation influences the experience of the students in a flipped classroom. The faculty in this study had no formal training in the flipped classroom and had not participated in previously flipped classroom environments. Having training in the flipped classroom may eliminate some of the unknowns the faculty in this study faced. These unknowns included: knowledge of student participation levels, ways to keep the students engaged, and alternate active learning activities.

Concept mapping was used as an active learning strategy for the flipped method in this study. Using concept 
mapping along with additional active learning strategies in the classroom may keep the students more engaged in the learning process. It was noted that the student became increasingly less engaged in active learning as the semester progressed. Utilizing a multitude of active learning strategies such as clickers, small group projects or interactive gaming in the classroom may hold the attention and enhance the learning experience of the students in the classroom.

The collection of some demographic data is also recommended for future studies. Some indicated demographic data that would benefit the study include age, gender, and previous learning experiences. Each of these factors may impact the results of the study. For example, Generation X students tend to embrace the traditional classroom and enjoy working independently. Asking these students to participate in group work may hinder their learning and engagement in the classroom. Generation X students embrace activities like case studies (Griggs, n.d.). Generation $\mathrm{Y}$ students enjoy working in groups and tend to have short attention spans, thus using a traditional approach may not be beneficial to them. (Griggs, n.d.). It would also be interesting to determine if there is a difference in success rates between genders in the flipped classroom.

Finally, it was difficult to determine if the students in the flipped classroom completed the pre-class reading assignments or listened to the online lectures prior to class. In future studies, ways to measure student preparation prior to class should be explored. Having the students complete a pre-class quiz or being able to determine if the students log on to the lecture may be beneficial. Ensuring students are preparing for class by completing the required reading and listening to the voice-over PowerPoint presentations can enhance student learning and subsequently may alter the results of the study. Faculty in this study had no indications if assimilation was occurring in the classroom. It was evident that some students had prepared for class because they were more engaged in class activities. However, evidence of pre-class preparation of those not actively involved in the concept mapping activities was difficult to determine. Therefore, there is a need for developing an evaluation criterion to evaluate and provide evidence that students completed their pre-class readings and assignments.

\section{Discussion}

With an estimated 1.05 million job openings for RNs by the year 2022, the need to graduate successful students in nursing programs is essential (Bureau of Labor Statistics, 2012). One way to aid in the success of students is to modify the traditional classroom and seek alternative methods of instruction. A popular method of instruction is the flipped classroom. In the flipped classroom, the instructor is no longer the center of focus, the students are. Reading assignments and PowerPoint presentations viewed outside of class time allow time for instructor-student and student-student active interactions in class. As a quality improvement effort, focusing on student success in a Pharmacology I course, a community college in Southwestern Michigan utilized a flipped classroom. Prior to the quality improvement effort, the student success rates (as demonstrated by a grade of $78 \%$ or higher on the comprehensive final examination), had reached levels as low as $50 \%$. PowerPoint presentations and reading assignments were posted on the learning management system. Students were expected to have viewed the PowerPoints and completed the reading assignments prior to face-face class time. While in the classroom setting, concept mapping was the tool of choice for active learning. Each concept map focused on the drug classification of interest for the week. The maps included the drug classification, drugs within the classification, adverse drug reactions, therapeutic uses, effects of the drugs on the body, and any other "drug specific" information deemed important to understand.

Although significant differences in success rates between the traditional and flipped classroom were not revealed by this study, the increased percentage of student success in the flipped classroom partially supported Ausubel's theory of assimilation. Giving meaning to the information presented to the student increases the student's retention of the information (Ausubel, 1968). By utilizing Bergmann and Sam's (2012) flipped classroom concept and presenting active learning activities in the classroom rather than providing a passive learning experience, the student's final examination grades in the flipped classroom setting showed a slight increase in their exam grades. Completing the pre-class activities helped the students to assimilate the knowledge, prepare them to be more active and engaged in in-class activities, and resulted in achieving a higher final examination.

When considering the community college setting that has a small nursing program any method that increases student success, even if not statistically significant should be explored and utilized because small increases in student success can have significant impacts on the program and the college. If the data from the Fall 2016 cohort is excluded from the study, implementing the flipped classroom in Pharmacology I not only increased the rates of student success but also showed an increase in the overall mean scores on the final examination. The results of this study indicate the flipped classroom method has a slightly positive impact on student success in 
the Pharmacology course and therefore should be used as a learning strategy in the nursing program.

While evaluating the results of this study, it was found that one cohort of students had significantly higher number of students that did not pass the final examination and the mean score on the final examination was significantly lower than that of any other cohort in the study. Due to these results, it is recommended that this specific cohort of students be monitored throughout the rest of the nursing program (an additional two semesters) to see if this trend continues or if this was an isolated incident. Excluding the student data from the sets did not make a statistically significant difference in the results. However, when the Fall 2016 cohort was removed from the data, a slight increase in final exam scores were noted.

Having a faculty member with experience in the flipped classroom may have strengthened the study. As with the students in the study, the faculty member conducting the flipped classroom was learning at the same time as the quality improvement effort progressed. Having experience in the flipped classroom prior to the initiation of a quality improvement effort may have made the faculty member more comfortable in the flipped classroom setting, therefore enhancing the experience for the students as well. Even without having an experienced faculty member as part of the quality improvement effort, the students generally expressed satisfaction with the flipped classroom method as indicated on their course evaluations.

Despite the limitations of this study, the results were similar to other studies focusing on the flipped classroom and student success. This supports Geist et al.'s (2015) assertions in that flipping the classroom can be used as an alternative teaching method without compromising student success. Further studies with larger sample sizes will determine whether the flipped teaching method should replace the traditional teaching method.

\section{Conclusions and Contributions to the Profession of Nursing}

The purpose of this study was to determine if a flipped teaching method using concept mapping as the primary form of active learning as opposed to a traditionally led, lectured based classroom would make a difference in student success rates in a Pharmacology I course at a community college in Southwestern Michigan. It can be the flipped classroom can be used as an alternative method of instruction in Pharmacology I without a significant difference in student success rates. This conclusion is supported by several other studies conducted in nursing education which found no significant differences in student success rates when utilizing a flipped classroom versus. a traditional classroom (Farretta, 2016; Geist et. al, 2015; Harrington et al., 2015). Although individual exam scores were higher in this study as well as previous studies, the differences were not large enough to be deemed significant.

The completion of this study has provided administrators at the college with evidence that supports using the flipped classroom can be an alternative teaching method in nursing education. With this gained knowledge nursing educators may be encouraged to continue to explore alternate methods of instruction in an effort to enhance the learning experience of the students. Quality improvement studies to enhance student engagement will continue to be a focus of higher education. This study has demonstrated that alternate means of information delivery and classroom instruction can have positive impacts on learning and examination scores.

\section{References}

Abel, W.M., \& Freeze, M. (2006). Evaluation of concept mapping in an associate degree nursing program. Journal of Nursing Education, 45(9), 356-364.

American Association of Colleges of Nursing. (2015). Leading initiatives/research and data/about data center. Retrieved from http://http://www.aacn.nche.edu/research-data/about-data-center

Atay, S., \& Karabacak, U. (2012). Care plans using concept maps and their effects on the critical thinking dispositions of nursing students. International Journal of Nursing Practice, 18, 233-239. https://doi.org/10.1111/j.1440-172X.2012.02034.x

Ausubel, D.P. (1968). Educational psychology: A cognitive view. New York: Holt, Rinehart, \& Winston.

Bergmann, J., \& Sams, A. (2012). Flip your classroom: Reach every student in every class every day.

Bureau of Labor Statics. (2012). Table 8. Occupations with the largest projected number of job openings due to growth and replacement needs, 2012 and projected 2022. Retrieved from http://data.bls.gov/cgi-bin/print.pl/news.release/ecopro.t08.htm

Burns, N., \& Grove, S.K. (2009). The practice of nursing research: Appraisal, synthesis, and generation of evidence (6th ed.). St. Louis, MO: Saunders Elsevier. 
Clayton, L.H. (2006). Concept mapping: An effective, active teaching-learning method. Nursing Education $\begin{array}{lcc}\text { Perspectives, } & \text { 27(4), } & 197-203 . \\ \text { http://www.merriam-webster.com/dictionary/hacker }\end{array}$

Concept. (2019). In Merriam-Webster.com. Retrieved March 7, 2019, from https://www.merriam-webster.com/help/citing-the-dictionary

Concordia Online Education. (2015). What is rote learning? A battle between memory and intelligence. Retrieved from http://education.cu-portland.edu/blog/curriculum-instruction/what-is-rote-learning/

Council on Physician and Nurse Supply. (2008, March). Finding solutions to the healthcare staffing shortage. Retrieved from http://http://www.aacn.nche.edu/media-relations/fact-sheets/nursing-shortage

Della Ratta, C.B. (2015, March/April). Flipping the classroom with team-based learning in undergraduate nursing education. Nurse Educator, 40(2), 71-74. https://doi.org/10.1097/NNE.0000000000000112

Edie, A.E. (2014, January). My flipping journey. Reflections of nursing leadership. Retrieved from http://www.reflectionsonnursingleadership.org/Pages/Vol139_4_Edie_FlippingJourney.aspx

Faretta, R.S. (2016). A causal-comparative inquiry into the significance of implementing a flipped classroom strategy in nursing education (Doctoral dissertation). Dissertation Abstracts International: Section A. Humanities and Social Sciences (3669159)

Faul, F., Erdfelder, E., Buchner, A., \& Lang, A.-g. (2009). Statistical power analyses using G*Power 3.1: Tests for correlation and regression analyses. Behavior Research Methods, 41, 1149-1160. https://doi.org/10.3758/BRM.41.4.1149

Foundation of Critical Thinking. (2015). Defining critical thinking. Retrieved from http://www.criticalthinking.org/pages/defining-critical-thinking/766

Gardner, B.K. (2007). Getting to "Got it". Retrieved from http://http://www.ascd.org/publications/books/107024/chapters/Cognitive-Structures@-What-They-Are-and -Why-They-Matter.aspx

Geist, M.J., Larimore, D., Rawiszer, H., \& Al Sager, A.W. (2015). Flipped versus traditional instruction and achievement in a baccalaureate nursing pharmacology course. Nursing Education Perspectives, 36(2), 114-115. https://doi.org/10.5480/13-1292

George, A., Geethankrishnan, R., \& D’Souza, P. (2014, January/February). Concept mapping. A child health $\begin{array}{llll}\text { nursing practical } & \text { exercise. Holistic } & \text { Nursing }\end{array}$ https://doi.org/10.1097/HNP.0000000000000001

Griggs, J. (n.d.). Generational learning styles (Generation $X$ and $Y$ ). Retrieved from http://www.fit.edu/ctle/documents/Course_Design/Generational\%20Learning\%20 Styles \%20Handout.pdf

Griswold, C.M. (2014). Understanding causes of attrition of 1st- and 2nd-year nursing students. Dissertation Abstracts International: Section B. Sciences and Engineering.

Harrington, S.A., Vanden Bosch, M., Schools, N., Beel-Bates, C., \& Anderson, K. (2015). Quantitative outcomes for nursing students in a flipped classroom. Nursing Education Perspectives, 36(3), 179-181. https://doi.org/10.5480/13-1255

IHMC. (2014-2015). Q-27 Ausubel's assimilation theory. Retrieved from http://http://cmapsinternal.ihmc.us/viewer/cmap/1FYDDGZ61-LXN6V-6BK

Instructional Design Fusions. (2010, June). Tools for metacognition. Retrieved from http://https://instructionaldesignfusions.wordpress.com/2010/06/28/metacognition

Maxwell, K. (2014). Evaluating the effectiveness if two teaching strategies to improve nursing students' knowledge, skills, and attitudes in quality improvement and patient safety. Dissertation Abstracts International: Section B. Sciences and Engineering.

McDonald, K., \& Smith, C.M. (2013). The flipped classroom for professional development: Part I. benefits and strategies. Journal of Continuing Education in Nursing, 44(10), 437-438. https://doi.org/10.3928/00220124-20130925-19

Michigan Senate. (2012). State Notes: Topics of legislative interest. Retrieved from http://www.senate.michigan.gov/sfa/publications/notes/2012notes/notesfal12bb.pdf

Moodle (2016, June). About Moodle. Retrieved from https://docs.moodle.org/31/en/About_Moodle 
Murray, L., McCallum, C., \& Petrosino, C. (2014). Flipping the classroom experience: A comparison of online learning to traditional lecture. Journal of Physical Therapy Education, 28(3). https://doi.org/10.1097/00001416-201407000-00006

National League for Nursing. Retention rates in RN programs. (2016). Retrieved from http://www.nln.org/newsroom/nursing-education-statistics/retention-rates-in-rn-programs

Novak J.D., Canas, A.J. (n.d.). The theory underlying concept maps and how to construct and use them: http://cmap.ihmc.us/docs/theory-of-concept-maps

Novak, J.D., \& Gowin, D.B. (1984). Learning how to learn. New York, NY: Cambridge University Press. https://doi.org/10.1017/CBO9781139173469

Pallant, J. (2013). SPSS survival manual: A step by step guide to data analysis using IBM SPSS (5th ed.). New York, NY: McGraw Hill.

Schoening, A. M., Selde, M. S., Goodman, J. T., Tow, J. C., Selig, C. L., Wichman, C., ... Galt, K.

A. (2015). Implementing collaborative learning in Prelicensure nursing curricula: Student perceptions and learning outcomes. Nurse Educator, 40(4), 183-188. https://doi.org/10.1097/NNE.0000000000000150

Stevenson, E.L., \& Gordon, H.A. (2014). Students as active learners and teaching partners in the clinical setting. Nurse Educator, 39(2), 52-53. https://doi.org/10.1097/NNE.0000000000000016

Toothaker, R. (2016). A phenomenological study of millennial students and traditional pedagogies. Dissertation Abstracts International: Section A. Humanities and Social Sciences

Vancek, J.E. (2009, January). Using a conceptual approach with concept mapping to promote critical thinking. Journal of Nursing Education.

Waltz, C.F., Jenkins, L.S., \& Han, N. (2014). The use and effectiveness of active learning methods in nursing and health professions education: A literature review. Nursing Education Perspectives, 35(6), 392-400. https://doi.org/10.5480/13-1168

Yeo, C.M. (2014, July). Concept mapping: A strategy to improve critical thinking. Singapore Nursing Journal, $2-7$.

Yildirim, B., Ozkahraman, S., \& Karabudak, S.S. (2011). The critical thinking teaching methods in nursing students. International Journal of Business and Social Science, 2(24), 174-182.

\section{Copyrights}

Copyright for this article is retained by the author(s), with first publication rights granted to the journal.

This is an open-access article distributed under the terms and conditions of the Creative Commons Attribution license (http://creativecommons.org/licenses/by/4.0/). 